\title{
Energy-saving and influencing factors of household electricity consumption in China
}

\author{
Ming Wen ${ }^{1,2}$, Yun Zhang ${ }^{1,2}$, Hao Xiao ${ }^{3}$, and Rui Huang ${ }^{3, *}$ \\ ${ }^{1}$ Hunan Key Laboratory of Energy Internet Supply-demand and Operation, 410004 Changsha, China \\ ${ }^{2}$ State Grid Hunan Electric Power Company Limited Economic \& Technical Research Institute, \\ 410004 Changsha, China \\ ${ }^{3}$ Hunan University, School of economics and trade, 410079 Changsha, China
}

\begin{abstract}
Energy conservation and environmental protection are crucial to green development. This article distinguishes the relationship between the electricity literacy, energy saving awareness and information feedback. We found that i) electricity literacy and information feedback are negatively correlated with electricity consumption, ii) there is a positive correlation between electricity consumption and living area, household income, permanent resident population and education level, iii) electricity consumption presents an inverted $\mathrm{U}$ shape with education level.
\end{abstract}

\section{Introduction}

Energy conservation and environmental protection is one of China's basic state policies and has been the focus of the whole society. According to the report of the 19th CPC National Congress, "To promote green development, we must promote comprehensive conservation and recycling of resources, promote a revolution in energy consumption and reduce energy consumption." ${ }^{[1]}$ In addition to technological progress, improving the consciousness of saving of the whole society is undoubtedly an important way to save resources. Therefore, changing the concept of residents' energy consumption and reducing energy waste has become an important breakthrough to solve the energy problems ${ }^{[2]}$.

At present, many scholars have done a lot of research on electric power energy, mainly in the following aspects: 1) related research on energy conservation awareness. Hori et al. (2013) ${ }^{[3]}$ and Wang et al. (2018) ${ }^{[4]}$ found that community and individual awareness of energy conservation will affect daily energy conservation activities. Lee $(2015)^{[5]}$ and Abrahamse et al. (2009) ${ }^{[6]}$ found that students who master more electricity knowledge are more able to make reasonable energy consumption behavior. 2) Studies on the influencing factors of energy consumption. In terms of age and family income, Dirk et al. (2012) ${ }^{[7]}$ found that the aging of population and the increase of family income were not conducive to the promotion of energy conservation. In terms of energy price and housing conditions, energy price and living area have a significant impact on household energy consumption expenditure, and rural household energy consumption depends on the price of electricity ${ }^{[8]}$.

"Corresponding author : ruihuanghr@126.com 
To sum up, the existing literature has some limitations in studying the relationship between energy conservation awareness and energy consumption behavior. This is mainly reflected in the lack of empirical analysis of the differences in energy consumption behavior based on large-scale questionnaire survey data in China. Compared with previous studies, the contributions of this article include three aspects: Firstly, we innovatively divide the main factors affecting electricity consumption into three aspects, including electricity literacy, awareness and feedback. Secondly, to observe the influence of various factors on electricity consumption behavior under different income levels. Thirdly, we find that education level and electricity consumption show an inverted $U$ shape, which increases first and then decreases with the improvement of education level.

\section{Model setting and data source}

Based on the literature survey above, the following measurement model was established to investigate the impact of energy conservation awareness indicators:

$$
\ln \text { energy }=\beta_{0}+\beta_{1} \text { awareness }+\beta_{2} \text { feedback }+\beta_{3} \text { literacy }+\beta_{4} X+\varepsilon
$$

Literacy indicates the degree to which people regard energy literacy. In this paper, the energy efficiency labels of the main electrical appliances (refrigerators) (from grade1 to 5) were selected as the measurement index, and set the five dummy variables. Awareness indicates the level of people know about energy. In this paper, "whether the policy of stepped electricity price is known" is selected as its measurement index and set as a dummy variable (if the stepped electricity price is known, the value is 1). Feedback means information feedback. The measurement index is "frequency of electricity payment" (if the electricity payment is paid once a month, the value is 1). X represents other control variables. $\varepsilon$ represents error term.

The control variables include city, age, gender, education level, actual living area of residents, annual income of residents, permanent household population, electricity price, etc. City represents the urban-rural dummy variable (defined as 1 for city and 0 for rural). Old represents the age dummy variable ( $>60$ years old is 1 ). Female represents gender (female is 1). Educate stands for education level, including five categories (uneducated, elementary, middle, high and college degree or above). Area is the actual living area. Income means annual income. POP is the number of people living in a household. Price represents the average price of electricity, which is calculated by dividing the monthly cost of electricity by the amount used.

The data are from the 2015 Chinese General Social Survey (CGSS2015). It adopted multi-stage stratified sampling method, and 10,968 valid questionnaires were completed from 478 villages in 28 provinces, municipalities and autonomous regions.

Table 1. Descriptive statistics.

\begin{tabular}{cccccc}
\hline variable & Observed & Mean & S.D. & Min & Max \\
\hline Electricity consumption & 2857 & 4.577 & 0.844 & 0 & 8.006 \\
literacy & 1899 & 1.635 & 0.865 & 1 & 5 \\
awareness & 3489 & 0.383 & 0.486 & 0 & 1 \\
feedback & 3489 & 0.644 & 0.479 & 0 & 1 \\
old & 10809 & 50.333 & 16.849 & 18 & 95 \\
female & 10809 & 0.531 & 0.499 & 0 & 1 \\
educate & 10780 & 2.992 & 1.267 & 1 & 5 \\
city & 10809 & 0.588 & 0.492 & 0 & 1 \\
income & 9718 & 10.508 & 1.149 & 5.298 & 16.118 \\
pop & 10776 & 0.945 & 0.499 & 0 & 2.565 \\
\hline
\end{tabular}




\begin{tabular}{cccccc}
\hline area & 10754 & 4.544 & 0.633 & 2.303 & 6.397 \\
price & 3073 & -0.187 & 0.791 & -3.188 & 4.748 \\
\hline
\end{tabular}

\section{The empirical analysis}

\subsection{The Baseline Regression}

Based on the model (1), this paper obtained the following basic regression results. As can be seen from Table 2, we can include four aspects: firstly, when the energy label of refrigerators represents energy literacy, it means they have higher energy literacy, have higher awareness of energy conservation, and can use energy more rationally. Secondly, when the feedback frequency is higher, the electricity consumption is less, that is, every $1 \%$ increase in the feedback frequency will reduce the electricity consumption by about $0.06 \%$. Thirdly, urban residents use more electricity than rural ones. In terms of education, it may be that high level of education is often associated with high income, for every $1 \%$ more urban residents, electricity consumption increases by about $0.3 \%$. Fourthly, education level and electricity consumption show an inverted $U$ shape, which increases first and then decreases with the improvement of education level. Otherwise, residential area, household income, household permanent resident population and average monthly electricity price have positive effects on household electricity consumption.

Table 2. Baseline regression result.

\begin{tabular}{ccccc}
\hline & $(1)$ & $(2)$ & $(3)$ & $(4)$ \\
\hline grade1 & $-0.355^{* * *}$ & $-0.352^{* * *}$ & $-0.257^{* *}$ & $-0.250^{* *}$ \\
& $(-2.89)$ & $(-2.75)$ & $(-2.00)$ & $(-2.23)$ \\
grade2 & $-0.364^{* * *}$ & $-0.365^{* * *}$ & $-0.286^{* *}$ & $-0.283^{* *}$ \\
& $(-2.91)$ & $(-2.81)$ & $(-2.17)$ & $(-2.48)$ \\
grade3 & $-0.423^{* * *}$ & $-0.422^{* * *}$ & $-0.366^{* * *}$ & $-0.370^{* * *}$ \\
& $(-3.18)$ & $(-3.05)$ & $(-2.66)$ & $(-3.04)$ \\
grade4 & $-0.421^{*}$ & $-0.481^{* *}$ & -0.361 & -0.229 \\
& $(-1.88)$ & $(-2.10)$ & $(-1.64)$ & $(-1.38)$ \\
Awareness & & $0.294^{* * *}$ & $0.180^{* * *}$ & $0.155^{* * *}$ \\
& & $(7.72)$ & $(4.71)$ & $(4.23)$ \\
Feedback & & $-0.078^{*}$ & $-0.066^{*}$ & -0.027 \\
& & $(-1.88)$ & $-1.68)$ & $(-0.71)$ \\
female & & -0.020 & -0.014 \\
& & $(-0.54)$ & $(-0.39)$ \\
old & & 0.051 & 0.054 \\
& & & $(1.16)$ & $(1.28)$ \\
city & & $0.364^{* * *}$ & $0.286^{* * *}$ \\
& & & $(8.02)$ & $(6.18)$ \\
edu2 & & $0.158^{* *}$ & 0.094 \\
edu3 & & $(2.28)$ & $(1.40)$ \\
& & $0.238^{* * *}$ & $0.116^{*}$ \\
edu4 & & $(3.48)$ & $(1.74)$ \\
edu5 & & $0.304^{* * *}$ & $0.179^{* *}$ \\
area & & $(4.00)$ & $(2.40)$ \\
pop & & $0.281^{* * *}$ & 0.108 \\
& & & $(3.52)$ & $(1.36)$ \\
& & & $0.158^{* * *}$ & $0.127^{* * *}$ \\
& & & $(4.60)$ & $(3.65)$ \\
& & $0.374^{* * *}$ & $0.270^{* * *}$ \\
& & & $(9.25)$ & $(6.62)$ \\
\hline
\end{tabular}




\begin{tabular}{ccccc}
\hline & $(1)$ & $(2)$ & $(3)$ & $(4)$ \\
\hline income & & & $0.147^{* * *}$ \\
& & & $(7.21)$ \\
price & & & $-0.303^{* * *}$ \\
& & & $-11.53)$ \\
Observations & 1584 & 1584 & 1575 & 1455 \\
R-squared & 0.004 & 0.042 & 0.162 & 0.285 \\
\hline
\end{tabular}

legend: $* \mathrm{p}<0.1,{ }^{* *} \mathrm{p}<0.05,{ }^{* * *} \mathrm{p}<0.01$

\subsection{Further test}

In the analysis of the regression model and in connection with the questionnaire, we found that income had a certain inhibiting and promoting effect on the ability to influence variables such as energy literacy and energy conservation knowledge. To discuss and verify this effect, this paper performed a piecemeal test of income. Four regression models with $25 \%, 50 \%$ and $75 \%$ as demarcation points were constructed. Relevant data description is shown in Table 3.

Table 3 shows that energy literacy and feedback have different influence on energy consumption in the case of different income levels. When the annual income is at the low income level, energy literacy has a greater impact on energy consumption among low-income groups. Under different income levels, the influence coefficient of energy saving knowledge on energy saving effect is different. It can be considered that this process is influenced by income and has a certain endogeneity. At the same time, the influence of awareness on electricity consumption is significantly positive and increases with the increase of income. We guess that low-income groups tend to pay more attention to the change of electricity price, which will significantly change their electricity consumption habits. However, high-income people pay less attention to electricity price, and the change of electricity price has little effect on their electricity consumption habits.

Table 3. Grouped regression analysis based on income.

\begin{tabular}{ccccc}
\hline Income $\%$ & $\begin{array}{c}0-25 \% \\
\text { (low income) }\end{array}$ & $25 \%-50 \%$ & $50 \%-75 \%$ & $\begin{array}{c}75 \%-100 \% \\
\text { (high income) }\end{array}$ \\
\hline grade_1 & $-0.7987^{* *}$ & -0.0546 & -0.1340 & $-0.4113^{* * *}$ \\
grade_2 & $-1.0590^{* * *}$ & -0.0546 & -0.0988 & $-0.4233^{* * *}$ \\
grade_3 & -0.6335 & $-0.3341^{* *}$ & -0.0838 & $-0.4888^{* * *}$ \\
grade_4 & $-1.3031^{* * *}$ & $-1.2076^{* * *}$ & -0.1616 & -0.0950 \\
awareness & 0.0909 & $0.1505^{* *}$ & $0.1686^{* *}$ & $0.1789^{* * *}$ \\
feedback & -0.0841 & 0.0944 & -0.0915 & $-0.1273^{*}$ \\
female & -0.0663 & 0.0011 & -0.0281 & -0.0103 \\
old & 0.1244 & 0.1291 & 0.0010 & 0.0000 \\
city & $0.4870^{* * *}$ & $0.1706^{* *}$ & $0.2662^{* * *}$ & $0.3774^{* * *}$ \\
edu2 & $0.2117^{*}$ & -0.0137 & 0.1774 & 0.2963 \\
edu3 & $0.2283^{*}$ & 0.1352 & 0.1942 & 0.1415 \\
edu4 & $0.4073^{* *}$ & 0.1268 & 0.2194 & 0.1766 \\
edu5 & $0.5182^{* * *}$ & 0.0310 & 0.1525 & 0.0402 \\
area & 0.0538 & 0.0521 & $0.1725^{* *}$ & 0.0843 \\
pop & $0.3672^{* * *}$ & $0.3221^{* * *}$ & $0.2152^{* * *}$ & $0.3297 * * *$ \\
price & $-0.3440^{* * *}$ & $-0.2944^{* * *}$ & $-0.3436^{* * *}$ & $-0.2846^{* * *}$ \\
cons & $4.2667^{* * *}$ & $3.7174^{* * *}$ & $3.3615^{* * *}$ & $4.2217^{* * *}$ \\
\hline
\end{tabular}

legend: $* \mathrm{p}<.1 ; * * \mathrm{p}<.05 ; * * * \mathrm{p}<.01$ 


\section{Conclusion and suggestion}

Based on the CGSS2015 data, this paper conducts the influence factors of electricity literacy, energy saving awareness and information feedback. We found that the higher the electricity literacy, the better the electricity efficiency. With the improvement of people's awareness of electricity saving, the effect of electricity saving is more obvious. We also found that the more frequently pay the electricity bill, the less electricity you use. In addition, education level and electricity consumption show an inverted $U$ shape. So, we will guide the society to create conditions for energy conservation and cultivate people's energy conservation habits. Then detailed policies to different groups should be made to promote the diversification of energy conservation policies. Finally, we should refine the content of information feedback and innovate the method of information feedback.

\section{References}

1. The State Council, Strategic action plan for energy development, 6, (2014)

2. The State Council, The 13th Five-year Plan for energy developmen, 12, (2016)

3. Hori, S., Kondo, K., Nogata, D., \& Ben, H., Energy Policy, 52(2013)

4. Wang, B., Wang, X., Guo, D., Zhang, B.,\& Wang, Z., Energy Policy, 116,( 2018)

5. Lee, L. S., Lee, Y. F., Altschuld, J. W., \& Pan, Y. J., Energy Policy, 76, 76(2015)

6. Abrahamse, W., \& Steg, L., Journal of Economic Psychology, 30,5(2009)

7. Brounen,D., Kok,N., \& Quigley,J. M., European Economic Review, 56, 5(2012)

8. Costa, D. L., \& Kahn, M. E., American Economic Review, 101, 3(2011) 